\title{
GAS CHROMATOGRAPHY-MASS SPECTROMETRIC ANALYSIS AND IDENTIFICATION OF BIOACTIVE CONSTITUENTS OF CATHARANTHUS ROSEUS AND ITS ANTIOXIDANT ACTIVITY
}

\author{
JYOTI RANI, MANISH KAPOOR*
}

\author{
Department of Botany, Punjabi University, Patiala, Punjab, India. Email: jdmanishkapoor@yahoo.com
}

Received: 22 November 2018, Revised and Accepted: 07 January 2019

\begin{abstract}
Objective: The main objectives of this study were analysis of the phytochemicals produced by two different Catharanthus roseus morphotypes, i.e., pink and white flowered and evaluate it morphologically and phytochemically in terms of total phenolic content (TPC), total flavonoid content
\end{abstract} (TFC), antioxidant properties, and gas chromatography-mass spectrometry (GC-MS) analysis.

Methods: Methanolic extracts of both morphotypes were prepared by Soxhlet apparatus. After extraction, the extracts were filtered and solvent removed by rotatory evaporator. TPC was determined by Folin-Ciocalteu reagent method and TFC was estimated by aluminum chloride colorimetric method. Antioxidant and free radical scavenging activities were estimated by superoxide dismutase and 1,1-diphenyl-2-picrylhydrazyl assay. GC-MS analysis was performed at Central Instrumentation Laboratory/ SAIF, Panjab University, Chandigarh.

Results: Pink-flowered C. roseus showed highest activities in terms of TPC, TFC, and antioxidant activity as compared to white-flowered $C$. roseus. 42 different bioactive compounds were detected in the methanolic extract of pink, while only 7 compounds were identified in white-flowered $C$. roseus. The identification was performed by GS-MS analysis mainly based on retention time, peak area, molecular formula, and molecular weight.

Conclusion: The finding indicated that the pink-flowered $C$. roseus was phytochemically superior then the white one.

Keywords: Catharanthus roseus, Total phenolic content, Total flavonoid content, Antioxidant properties, Gas chromatography-mass spectrometry.

(C) 2019 The Authors. Published by Innovare Academic Sciences Pvt Ltd. This is an open access article under the CC BY license (http://creativecommons. org/licenses/by/4. 0/) DOI: http://dx.doi.org/10.22159/ajpcr.2019.v12i3.

\section{INTRODUCTION}

Plants play a potential role, especially in the production of herbal medicine and pharmaceutical medications. A significant proportion of the world population relies on herbal and customary medicine due to the high costs and lack of orthodox medicine [1]. The modern medicine productions also rely on medicinal plant-derived therapeutic components. Many medicinal plants contain an assortment of pharmaceutical components which have an extremely fundamental role in the fields of veterinary and human prescription. Plant-based items play a dominant role in the development of novel drug leading to the treatment and prevention of diseases [2-4].

History reveals that plants are important sources of drugs and will continuously be essential for the discovery of new lead compounds [5]. The most essential bioactive constituents of the plants are phenols, alkaloids, cardiac glycoside, tannins, and flavonoid compounds. In India, medicinal plants are of great interest to the field of plant biotechnology, as most of the pharmaceutical industries depend on plants for the production of therapeutic compounds [6].

Catharanthus roseus (family: Apocynaceae) popularly known as Madagascar periwinkle or Vinca, grown as evergreen ornamental herbaceous plant in gardens throughout the world [7], flower having five petals and various colors including pink, red, white and purple. However, nowadays, this plant is mainly cultivated for its alkaloids, having antileukemic activities [8]. It is a subshrub plant growing up to $1 \mathrm{~m}$ tall. The plant has been used to treat a vast range of the assortment of diseases [9]. In India, leaf juice is used to treat wasp stings. In China, this plant is used as a diuretic, astringent, menstrual regulation, and cough remedy. In South America, it is used as a folk remedy for inflammation and cold. In Caribbean region, flower extract is mainly used to treat infection and irritation. In England and Brazil, entire dried plant extract is taken orally along with hot water to treat diabetes mellitus. In Australia, hot water extract of leaves is used to treat diabetes and menorrhagia [10].
A detailed literature survey about the medicinal properties of $C$. roseus leaves revealed it to possess antileukemic, antioxidant, antimicrobial, and anti-inflammatory activities [11]. The medicinal properties are attributed to the presence of alkaloids and phenolic compounds in its leaf extract. Therefore, it was essential to screen the methanolic extract of $C$. roseus leaves for the detection of phytochemicals, to identify and characterize phytoconstituents in its crude extracts for chemical profiling using gas chromatography-mass spectrometry (GC-MS) analytic technique, to evaluate its antioxidant potential using in vitro methods, and to correlate with the phenolic and flavonoid content.

\section{METHODS}

The current study involved two different morphotypes of C. roseus, differing in petal color, shape, arrangement of petal and color of eye, grown naturally in the Botanical Garden and Department of Botany, Punjabi University, Patiala (Table 1 and Fig. 1). Flower petal was separated as pink and white. The voucher specimen of $C$. roseus was identified and deposited in Herbarium (PUN) at the Department of Botany, Punjabi University Patiala.

\section{Plant material}

C. roseus leaves were collected in June 2015. The collected leaf material was washed thoroughly with tap water to remove dust particles and dried under the shade at room temperature for 6-7 days. The dried leaves were ground to obtain the fine powder and kept in airtight glass bottles, until further use.

\section{Extraction of plant material}

Extraction of plant material was done with methanol: water (1:1) using Soxhlet apparatus. After the completion of extraction, the extract was filtered and solvent was removed by rotary evaporator.

Phytochemical screening of leaf extract

The freshly prepared methanolic crude leaf extract was subjected to qualitative analysis to identify various bioactive constituents present 
Table 1: Morphological characteristics of two morphotypes of C. roseus

\begin{tabular}{llll}
\hline Morphotypes & $\begin{array}{l}\text { Petal } \\
\text { color }\end{array}$ & $\begin{array}{l}\text { Petal } \\
\text { arrangement }\end{array}$ & Eye color \\
\hline Catharanthus roseus & Pink & Overlap & Red \\
Catharanthus roseus & White & Free & Yellow \\
\hline
\end{tabular}

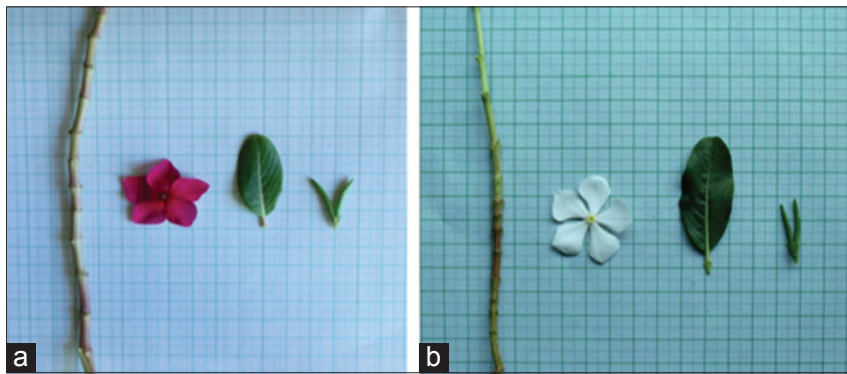

Fig. 1: Morphological features of two Catharanthus roseus morphotypes (a) pink and (b) white

in the leaves using standard procedures. The crude extract was also subjected for GC-MS analysis to identify the various phytochemical constituents present in the plant extracts.

\section{Total phenolic content (TPC)}

TPC was estimated by Folin-Ciocalteu reagent method. Phenols which react with phosphomolybdic acid in Folin-Ciocalteu reagent in the alkaline medium will produce a blue-colored complex (molybdenum blue) which can be estimated spectrophotometrically at $650 \mathrm{~nm}$. A stock solution of plant extracts was prepared to $1 \mathrm{mg} / \mathrm{mL} .5 \mathrm{~mL}$ of Folin- Ciocalteu and $2 \mathrm{~mL}$ of $\mathrm{Na}_{2} \mathrm{CO}_{3}$ were added to the $1 \mathrm{~mL}$ of plant sample. The solution was vortexed and incubated in the dark for $15 \mathrm{~min}$. The absorbance was measured at $650 \mathrm{~nm}$. Blank consisted of $5 \mathrm{~mL}$ Folin-Ciocalteu, $1 \mathrm{~mL}$ solvent, and $2 \mathrm{~mL}$ of $\mathrm{Na}_{2} \mathrm{CO}_{3}$ solution. Gallic acid was used as a standard of $10-100 \mu \mathrm{g} / \mathrm{mL}$ range from a stock solution of $1 \mathrm{mg} / \mathrm{mL}$. The TPC was calculated from the calibration curve, and the result was expressed in terms of $\mathrm{mg}$ of gallic acid equivalent per gram dry weight. All tests were performed in triplicates [12].

\section{Total flavonoid content (TFC)}

TFC was estimated by aluminum chloride colorimetric method with some modifications to determine flavonoid content. $1 \mathrm{~mL}$ of plant sample was added to $3 \mathrm{~mL}$ of methanol, $0.2 \mathrm{~mL}$ of $10 \%$ aluminium chloride, $0.2 \mathrm{~mL}$ of $1 \mathrm{M}$ potassium acetate and $5.6 \mathrm{~mL}$ of distilled water and kept at room temperature for $30 \mathrm{~min}$. The absorbance was measured at $420 \mathrm{~nm}$. Quercetin was used as standard of $10-100 \mu \mathrm{g} / \mathrm{mL}$ range from $1 \mathrm{mg} / \mathrm{mL}$ stock solution. All the tests were performed in triplicates. Flavonoid contents were determined from the calibration curve, and a result was expressed as mg of quercetin equivalent (per g of extracted compound) [13].

\section{Antioxidant activity}

Superoxide dismutase (SOD)

SOD levels in the cell-free supernatant were measured by the method of Kono [14]. Briefly, $1.9 \mathrm{~mL}$ of sodium carbonate buffer $(50 \mathrm{mM}$, $\mathrm{pH} 10.0$ ), $750 \mu \mathrm{L}$ of nitrobluetetrazolium dye (NBT), and $240 \mathrm{mM}$ and $150 \mu \mathrm{L}$ of $0.3 \%$ Triton $\mathrm{X}$ - 100 were added to the test cuvette. The reaction was initiated by the addition of $150 \mu \mathrm{L}$ of hydroxylamine hydrochloride ( $10 \mathrm{mM}, \mathrm{pH}$ 6.0). After $2 \mathrm{~min}, 70 \mu \mathrm{L}$ enzyme samples from the plant tissue were added. The percentage inhibition in the rate of NBT reduction was recorded as an increase in absorbance at $560 \mathrm{~nm}$. The percentage inhibition of NBT reduction was calculated as follows:

\author{
Change in absorbance/minute (Control) - \\ $\mathrm{X}=\frac{\text { Change in absorbance } / \text { minute } \text { (Test) }}{\text { Chnage in absorbance } / \text { minute (Control) }} \times 100$
}

$\mathrm{X} \%$ of inhibition is produced by $70 \mu \mathrm{L}$ of sample.

Hence, $50 \%$ inhibition is produced by

Y $\mu$ L of sample $=\frac{50 \times 70}{\mathrm{X}} \times 100$

\section{Free radical scavenging activity}

The free radical scavenging activity of leaves was measured using 1,1-diphenyl-2-picrylhydrazyl (DPPH) [15]. This method depends on the reduction of purple color of DPPH to yellow color diphenylpicrylhydrazine. A stock solution of leaf extracts was prepared to $1 \mathrm{mg} / \mathrm{mL}$ in methanol. Each stock solution diluted from $10 \mu / \mathrm{mL}$ to $100 \mu \mathrm{g} / \mathrm{mL} .1 \mathrm{~mL}$ of $0.3 \mathrm{mM}$ DPPH solution was added to $2.5 \mathrm{~mL}$ of sample solution. Ascorbic acid was used as standard with the same $1 \mathrm{mg} / \mathrm{mL}$ stock solution of different concentrations from $10 \mu \mathrm{g} / \mathrm{mL}$ to $100 \mu \mathrm{g} / \mathrm{mL}$. The sample was incubated in the dark for $30 \mathrm{~min}$. The absorbance was measured at $517 \mathrm{~nm}$. The absorbance was converted into percentage antioxidant activity using the following equation:

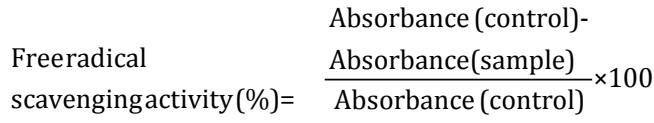

\section{Statistical analysis}

A statistical analysis of data was performed in accordance with the procedure given by Gomez and Gomez [16] and was analyzed as per completely randomized design [17] to test the significance of differences between the treatments. A coefficient of variation was calculated using the method given by Burton and Devane [18].

\section{GC-MS analysis}

GC analysis was carried out at Central Instrumentation Laboratory/SAIF, Panjab University, Chandigarh.' This technique is very important for the identification of various phytochemicals of plant. The equipment used for GC-MS was QP-2010 Ultra. For GC-MS detection, an electron ionization system with ionizing energy of $70 \mathrm{eV}$ was used. Helium gas $(99.999 \%)$ was used as the carrier gas at a constant flow rate of $1 \mathrm{~mL} / \mathrm{min}$ and and $1 \mu \mathrm{L}$ of plant sample was employed (split ratio of $10: 1$ ), at injector temperature $250^{\circ} \mathrm{C}$, ion-source temperature of $280^{\circ} \mathrm{C}$, and total running time for a sample of about $76 \mathrm{~min}$.

\section{Identification of the components}

Interpretation of GC-MS was conducted using the database of National Institute Standard and Technology (NIST) having $>6200$ patterns. The spectrum of the unknown component was compared with the spectrum of the known component in the repository of NIST library. The retention time, molecular weight, molecular formula, and composition percentage of the sample material were recorded.

\section{RESULTS}

TPC and TFC of leaf extracts are expressed in terms of gallic acid and quercetin, respectively, and presented in Table 2. C. roseus pink morphotype extract showed highest phenolic and flavonoid content as compared to the white morphotype leaf extract. The antioxidant activities were investigated by commonly used free radical scavenging methods such as DPPH and SOD. The scavenging effect of leaf extracts on the DPPH free radicals was expressed as percentage inhibition, and they were compared with standard antioxidant, ascorbic acid. Lower $\mathrm{IC}_{50}$ value indicates the higher antioxidant 
activity. The pink morphotype showed highest while the white one showed minimum antioxidant activity. Similar trend was observed for SOD activity.

GC-MS analyzed the results which include the active principles with their molecular formula, molecular weight, retention time, peak area \%, and composition of the bioactive components of $C$. roseus which are presented in Tables 3 and 4. The GC-MS chromatogram of the detected compounds is as shown in Fig. 2.

Many significant physiological active components were identified from both the samples by GC-MS. Chlorozotocin ( $0.17 \%), 2$-Pyrrolidinone, 1-butyl- $(0.13 \%)$, Ethyl $\mathrm{N}$-(o-anisyl) formimidate $(0.36 \%)$, 2-Pentyne1,4-diol, 4- methyl-1-(2-thienyl)- (0.33\%), Cis-Inositol (0.09\%), Muco-Inositol (2.38), 3-Phenylbicyclo (3.2.2) nona-3,6-dien-2-one $(0.06 \%), 9,12,15$-Octadecatrienoic acid, methyl ester $(2.70 \%)$, 9-Octadecynoic acid (3.24\%), Methyl 8,11,14-heptadecatrienoate (30.04\%), [1,1'-Bicyclopropyl]-2-octanoic acid, 2'-hexyl-, methyl ester (0.20\%), Condyfolan, 14,19-didehydro-12-methoxy-,(14E)- (0.29\%) and 2,20-Cycloaspidospermidine-3-carboxylic acid (1.05).

C. roseus white morphotype contained seven different components such as 1-4H-Pyran-4-one (4.73\%), 5-Hydroxymethylfurfural (30.86\%), n-Hexadecanoicacid(6.58\%),phytol(17.17\%),9,12,15-Octadecatrienoic acid, (Z,Z,Z)- (23.64\%), 2,20-Cycloaspidospermidine-3-carboxylic acid (4.95\%), and Aspidospermidine-3-carboxylic acid (12.09\%).

Antioxidant and antimicrobial activities are shown by various identified compounds such as 4H-Pyran-4-one, Benzofuran, 2,3-dihydro, 1,2,3-Propanetriol, 1-acetate/acetin, l-Gala-l-ido-octonic lactone, desulfosinigrin, 3',5'-Dimethoxyacetophenone, $\alpha$-D-Glucopyranoside, O- $\alpha$-D-glucopyranosyl-(1.fwdarw.3)-ß-d-fru, 1,2,3,5-Cyclohexanetetrol, 2-Methyl-9-a-d-ribofuranosylhypoxanthine, Myo-Inositol, 4-C-methyl-, Hexadecanoic acid, methyl ester, pentadecanoic acid, dasycarpidan-1methanol, acetate (ester, Phytol, Methyl 8,11,14-heptadecatrienoate, [1,1'-Bicyclopropyl]-2-octanoic acid, 2'-hexyl-, methyl ester, and Phthalic acid, di(oct-3-yl) ester.

\section{DISCUSSION}

In the present study, a total of 42 compounds were identified in pink morphotypes and seven in white morphotype of Catharanthus. In terms of percentage amount, methyl 8,11,14-heptadecatrienoate, 9-octadecynoic acid, 9,12,15-octadecatrienoic acid, methyl ester, pentadecanoic acid, 1,2,3,5-Cyclohexanetetrol, muco-inositol, and sucrose were prominent in pink morphotype, whereas 5-Hydroxymethylfurfural, 9,12,15-octadecatrienoic acid, and phytol were prominent in white morphotypes. Identified compounds having anti-inflammatory, antimicrobial, antioxidants, and antiproliferative activity have been identified. The plant is mainly used due to its antineoplastic properties.

Among the identified compounds, 5-hydroxymethylfurfural is a sugar component and showed antioxidant and antiproliferative activity previously reported by Hussein [19]. 9,12,15-Octadecatrienoic acid $(\mathrm{Z}, \mathrm{Z}, \mathrm{Z})$ - and 9,12,15-Octadecatrienoic, methyl ester (Z,Z, Z)- which is a linoleic acid and reported to have an anticancer, anti-arthritic, antiinflammatory, anti-acne, hypocholesterolemic, hepatoprotective, antihistaminic, nematicide and insectifuge properties. Similarly, the presence of 9-octadecenoic acid was observed in the ethanolic root extract of Plumbago zeylanica by Ajayi et al. [20]. Hexadecanoic acid methyl ester is also known as palmitic acid ester and effectively used as an antioxidant, pesticide, anti-androgenic, nematicide, flavoring agent, hypocholesterolemic, and lubricant $[21,22]$. Carbohydrates such as mannitol and sucrose are present in a considered amount in methanolic extracts of Catharanthus. The GC-MS analysis revealed that the methanolic extract of $C$. roseus pink morphotype is composed of more oxygenated hydrocarbons and predominantly phenolic hydrocarbons as compared to the white morphotype. These phytochemicals are responsible for various pharmacological actions such as antimicrobial, antioxidant, and antiproliferative activity. Results showed that components from both of the two morphotypes are a complex mixture of numerous compounds, many of which are found in trace amount. It is worth monitoring that there is a great variation in the chemical composition of these two morphotypes of $C$. roseus. This confirms that the reported variation in phytoconstituents is due to morphological variation between the two accessions.

The results of GC-MS testing indicated that $C$. roseus leaves contained numerous bioactive phytoconstituents belonging to various classes such as tannins, glycosides, alkaloids, flavonoids, and steroids. The leaf extract quantification, by colorimetric methods, was found to be rich in phenolic compounds (flavonoids) and therefore exhibited very good scavenging activity against DPPH and SOD free radicals. Based on the results, it can be concluded that $C$. roseus leaves could be used as a natural source of antioxidants and its regular consumption in diet could provide health benefits to humans by protecting against oxidative stress. Further detailed in vitro and in vivo correlation studies along with isolation of active constituents are needed to unravel novel treatment strategies for free radical-induced diseases.

\section{CONCLUSION}

The study reveals the presence of bioactive compounds of the methanolic extract of $C$. roseus leaves. The present study can provide

Table 2: TPC, TFC, and antioxidant activities of two morphotypes of Catharanthus roseus

\begin{tabular}{lllll}
\hline Morphotypes & DPPH assay $\left(\mathbf{I C}_{\mathbf{5 0}}\right) \boldsymbol{\mu g} / \mathbf{m l}$ & SOD & $\begin{array}{l}\text { TPC }(\mathbf{m g} \text { gallic acid equivalent per g of } \\
\text { leaves) }\end{array}$ & $\begin{array}{l}\text { TFC }(\mathbf{m g} \text { quercetin equivalent per g of } \\
\text { leaves) }\end{array}$ \\
\hline $\begin{array}{l}\text { Catharanthus } \\
\text { roseus (Pink) }\end{array}$ & $10.62 \pm 2.42$ & $123 \pm 0.42$ & $40.8 \pm 0.52$ & $12.4 \pm 0.77$ \\
$\begin{array}{l}\text { Catharanthus } \\
\text { roseus (White) }\end{array}$ & $25.95 \pm 1.32$ & $88 \pm 1.05$ & $15.3 \pm 1.12$ & $9.82 \pm 0.67$ \\
\hline
\end{tabular}

Values are the average of triplicate experiments and values expressed as mean \pm SEM, SEM: Standard error of mean, SOD: Superoxide dismutase, TPC: Total phenolic content, TFC: Total flavonoid content, DPPH: 1,1-diphenyl-2-picrylhydrazyl

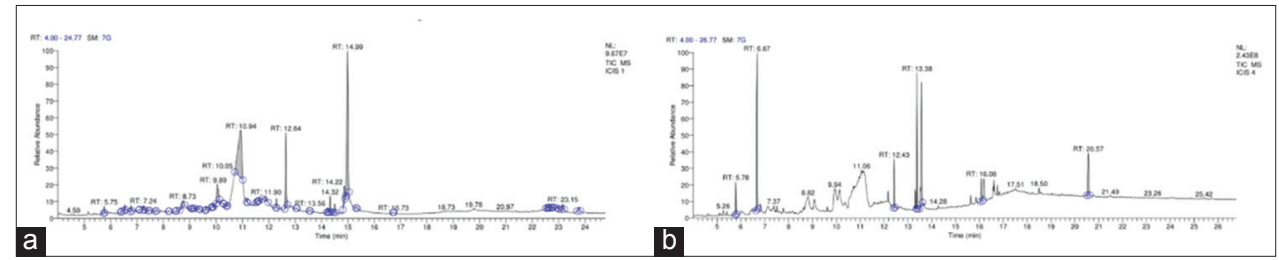

Fig. 2: Chromatogram of the leaf methanolic extract of Catharanthus roseus (a) pink and (b) white 
Table 3: Results of the GC-MS analysis from the leaves of Catharanthus roseus (pink)

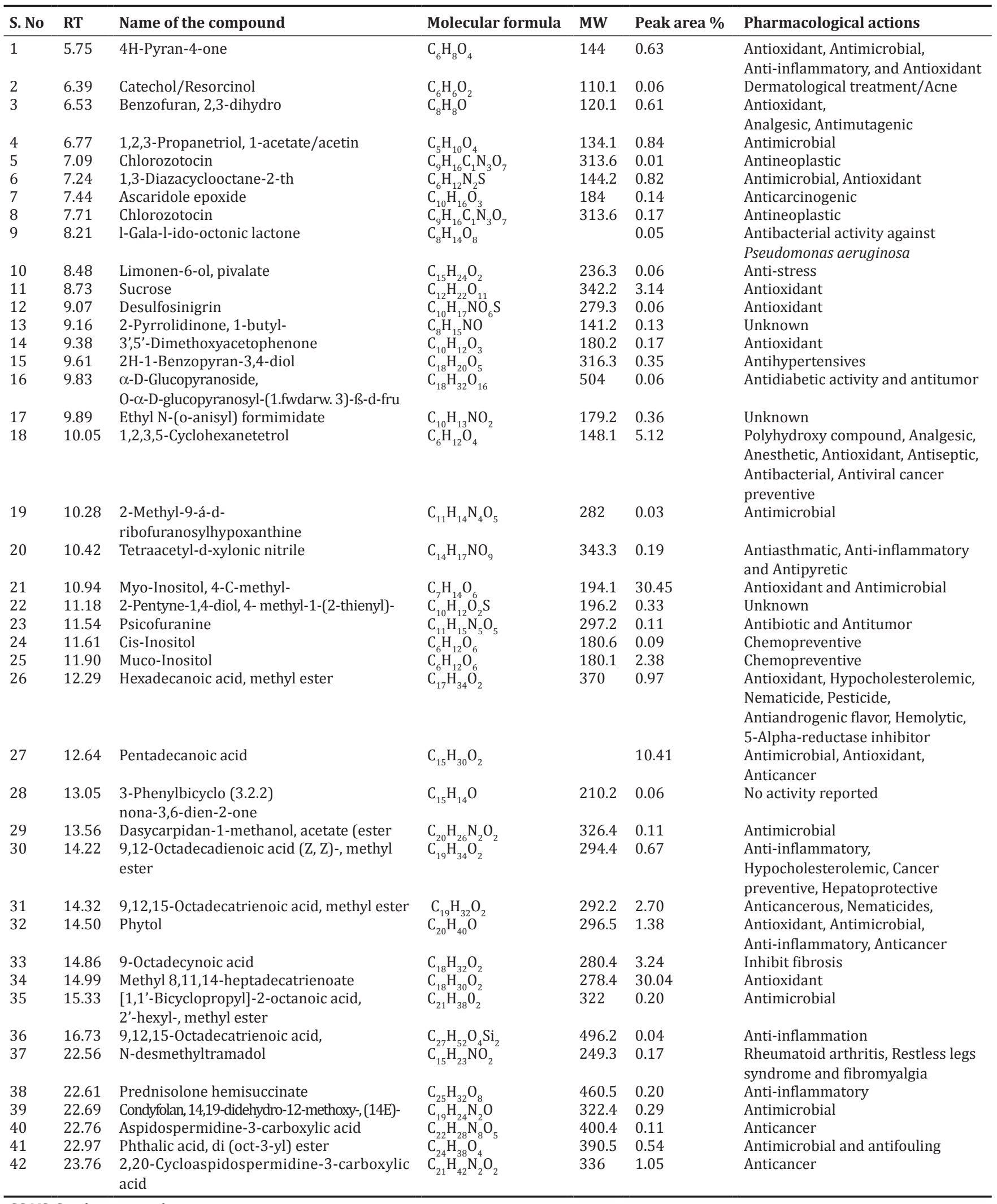

GC-MS: Gas chromatography-mass spectrometry

a good concrete base for further research to isolate the lead bioactive compounds in the leaves to develop new antioxidant and antimicrobial agent.

\section{AUTHORS' CONTRIBUTIONS}

Manish Kapoor conceptualized the research and framework and supervised it. Jyoti Rani performed all the experimental work. Both the 
Table 4: Results of the GC-MS analysis from the leaves of Catharanthus roseus (white)

\begin{tabular}{|c|c|c|c|c|c|c|}
\hline S. No & RT & Name of the compound & Molecular formula & MW & Peak Area \% & Pharmacological actions \\
\hline 1 & 5.78 & 4H-Pyran-4-one & $\mathrm{C}_{6} \mathrm{H}_{8} \mathrm{O}_{4}$ & 144 & 4.73 & $\begin{array}{l}\text { Antioxidant, Antimicrobial, } \\
\text { Anti-inflammatory, and Antioxidant }\end{array}$ \\
\hline 2 & 6.67 & 5-Hydroxymethylfurfural & $\mathrm{C}_{3} \mathrm{H}_{6} \mathrm{O}_{3}$ & 126 & 30.86 & Antioxidant, Antiproliferative activity \\
\hline 3 & 12.43 & n-Hexadecanoic acid & $\mathrm{C}_{16}^{3} \mathrm{H}_{32}^{6} \mathrm{O}_{2}$ & 256 & 6.58 & $\begin{array}{l}\text { Antioxidant, Hypocholesterolemic, } \\
\text { Nematicide, Pesticide, Lubricant, } \\
\text { Antiandrogenic, Flavor }\end{array}$ \\
\hline 4 & 13.38 & Phytol & $\mathrm{C}_{20} \mathrm{H}_{40} \mathrm{O}$ & 296 & 17.17 & $\begin{array}{l}\text { Hypocholesterolemic, Antimicrobial, } \\
\text { Anticancer, Diuretic, Anti-inflammatory }\end{array}$ \\
\hline 5 & 13.57 & $9,12,15$-Octadecatrienoic acid & $\mathrm{C}_{18} \mathrm{H}_{30} \mathrm{O}_{2}$ & 278 & 23.64 & $\begin{array}{l}\text { Anti-inflammatory, Hypocholesterolemic, } \\
\text { Cancer preventive, Hepatoprotective, } \\
\text { Nematicide, Insectifuge }\end{array}$ \\
\hline 6 & 16.08 & $\begin{array}{l}\text { 2,20-Cycloaspidospermidine } \\
\text {-3-carboxylic acid vindolinine }\end{array}$ & $\mathrm{C}_{21} \mathrm{H}_{24} \mathrm{~N}_{2} \mathrm{O}_{2}$ & 336 & 4.95 & Anticancer \\
\hline 7 & 20.57 & $\begin{array}{l}\text { Aspidospermidine-3-carboxylic acid } \\
\text { vindoline }\end{array}$ & $\mathrm{C}_{22} \mathrm{H}_{28} \mathrm{~N}_{2} \mathrm{O}_{5}$ & 400 & 12.09 & Anticancer \\
\hline
\end{tabular}

GC-MS: Gas chromatography-mass spectrometry

authors analyzed the data and interpreted the results. Jyoti Rani and Manish Kapoor wrote and finalized the manuscript.

\section{CONFLICTS OF INTEREST}

Both the authors declare that there are no conflicts of interest regarding the publication of this research.

\section{REFERENCES}

1. Peter MP, Raj JY, Sicis VP, Joy V, Saravanan J, Sakthivel S. GC-MS analysis of bioactive components on the leaves extract of Stylosanthes fruticosa-a potential folklore medicinal plant. Asian J Plant Sci Res 2012;2:243-53.

2. Azalework HG, Sahabjada, Jafri A, Arshad MD, Malik T. Phytochemical investigation, GC-MS profile and antimicrobial activity of a medicinal plant Ruta graveolens L. from Ethiopia. Int J Pharm Pharm Sci 2017;9:21-6.

3. Newman DJ, Cragg GM, Snadder KM. Natural products as sources of new drugs over the Newman period, 1981-2002. J Nat Prod 2003;66:1022-37.

4. Oluduro AO. Evaluation of antimicrobial properties and nutritional potentials of Moringa oleifera Lam. Leaf in South-Western Nigeria. Malays J Microbiol 2012;8:59-67.

5. Velmurugan P, Kamaraj M, Prema D. Phytochemical constituents of Cadaba trifoliata Roxb. root extract. Int J Phytomed 2010;2:379.

6. Christopher L, Abboah-Offei O. Anticancer properties of some ornamental plants on KNUST campus, Kumasi, Ghana. Int J Phytopharmacol 2011;5:366-70.

7. Jaleel CA, Gopi R, Sankar B, Manivannan P, Kumar KA, Sridharan R, et al. Studies on germination, seedling vigour, lipid peroxidation and proline metabolism in Catharanthus roseus seedlings under salt stress. S Afr J Bot 2007:73:190-5.

8. Rashmi R, Trivedi MP. Assessment of variations in different cultivars of Catharanthus roseus by using restriction endonuclease and rapid PCR. Int J Pure Appl Biosci 2014;2:336-242.
9. Patil PJ, Ghosh JS. Antimicrobial activity of Catharanthus roseus-a detailed study. Br J Pharmacol Toxicol 2010;1:40-4

10. Sain M, Sharma V. Catharanthus roseus (an anti-cancerous drug yielding plant)-a review of potential therapeutic properties. Int J Pure Appl Biosci 2013;1:139-42.

11. Jacobs DI, Snoeijer W, Hallard D, Verpoorte R. The Catharanthus alkaloids: Pharmacognosy and biotechnology. Curr Med Chem 2004;11:607-28.

12. Singleton VL, Rossi JA. Colorimetry of total phenolics with phosphomolybdic-phosphotungstic acid reagents. J Enol Vitic 1965;16:144-58.

13. Park YS, Jung ST, Kang SG, Heo BG, Arancibia-Avila P, Toledo F, et al. Antioxidants and proteins in ethylene-treated kiwifruits. Food Chem 2008;107:640-8

14. Kono Y. Generation of superoxide radical during autoxidation of hydroxylamine and an assay for superoxide dismutase. Arch Biochem Biophys 1978;186:189-95.

15. Blois MS. Antioxidant determination by the use of a stable free radical. Nature 2002;26:1199-200

16. Gomez LA, Gomez AA. Statistical Procedure for Agricultural Research. $3^{\text {rd }}$ ed. Singapore, MA: John Wiley and Sons; 1984.

17. Snedecor GW, Cochran WG. Statistical Method. $5^{\text {th }}$ ed. Ames, Iowa: Iowa State University Press; 1980. p. 456.

18. Burton GN, Devane EM. Estimating heritability in fall Fescue (Festuca arundiancea L.) from replicated clonal materials. Agron J 1953;45:478-81.

19. Hussein HM. Analysis of trace heavy metals and volatile chemical compounds of Lepidium sativum using atomic absorption spectroscopy, gas chromatography-mass spectrometric and fourier-transform infrared spectroscopy Res J Pharm Biol Chem Sci 2016;2529-55.

20. Ajayi GO, Olagunju JA, Ademuyiwa O, Martins OC. GC-MS analysis and phytochemical screening of ethanolic root of Plumbago zeylanica (Linn.). J Med Plants Res 2011;5:1756-61.

21. Karthikeyan AV, Sudan I. GC-MS profile of in-vivo and in-vitro shoots of Cleome gynandra L. Int J Pharm Pharm Sci 2017;9:21-6.

22. Archana D, Dixitha M, Santhy M. Antioxidant and anti-clastogenic potential of Piper longum L. Int J Appl Pharm 2015;7:11-4. 